\title{
A Universidade Fluminense em tempos de calamidade pública: reflexões baseadas nos textos de Darcy Ribeiro
}

Leonardo Nolasco-Silva - Universidade do Estado do Rio de Janeiro (UERJ)

Vittorio Lo Bianco - Fundação Centro de Educação a Distância (CECIERJ)

\begin{abstract}
Resumo
Neste texto usaremos a obra de Darcy Ribeiro para pensarmos a situação atual do estado do Rio de Janeiro, tentando identificar em seus escritos algumas contribuições que podem nos ajudar a entender os ritos hoje praticados pelo governo do estado no que concerne ao trato pouco amigável dispensado às universidades e demais instituições correlatas. A obra de Darcy nos servirá de mapa e buscaremos discutir, com base em seus textos, o sentido e a crise da universidade, bem como o lugar por ela ocupado na produção de um projeto de Nação, observando no presente e no passado recente as aproximações e os desvios deste pensamento que conferia centralidade ao Ensino Superior para o desenvolvimento de uma sociedade mais igualitária.
\end{abstract}

Palavras-Chave: Universidade; Darcy Ribeiro; Pensamento-Ação.

\section{The Fluminense University in times of public calamity: reflections based on Darcy Ribeiros's texts.}

\begin{abstract}
In this text we will use the work of Darcy Ribeiro to think about the present situation of Rio de Janeiro state, trying to identify in his writings some contributions that may help us to understand the rites practiced today by the government of the state, regarding the unfriendly treatment to the universities and other correlated institutions. Darcy's work will serve as a map and we will seek to sketch, in his texts, the meaning of the crisis of the university, the place it occupies in the production of a nation project, observing in the present and in the recent past the approximations and deviations of this thought that conferred centrality to higher education for the development of a more egalitarian society.
\end{abstract}

Keywords: University; Darcy Ribeiro; Thought-Action.

\section{A Universidade Fluminense em tempos de calamidade pública: reflexões baseadas nos textos de Darcy Ribeiro}

\section{Introdução}

Revistar autores clássicos que, em seu tempo, com os limites impostos pelo até então sabido, propuseram pensar o Brasil e o povo brasileiro, interrogando a nossa história sobre motivações e movimentos em prol de um pensamento genuinamente nacional, é tarefa necessária e, ao mesmo tempo, arriscada.

Necessária porque ainda nos faltam elementos para compreender os caminhos tomados para que chegássemos à atual conjuntura; arriscada porque toda visitação teórica implica 
atualização e apropriação e, quanto a isso, não há instrumentos que nos protejam dos equívocos. Neste texto, por exemplo, usaremos a obra de Darcy Ribeiro para pensarmos o presente do estado do Rio de Janeiro, tentando identificar em seus escritos alguns pontos que nos ajudem a entender os ritos hoje praticados pelo estado no que concerne ao trato pouco amigável dispensado às universidades e demais instituições correlatas. A obra de Darcy nos servirá de mapa e buscaremos dimensionar nos seus textos, søbre o sentido da crise da universidade, o lugar por ela ocupado na produção de um projeto de Nação, observando no presente e no passado recente as aproximações e os desvios deste pensamento que conferia centralidade ao Ensino Superior para o desenvolvimento de uma sociedade mais igualitária.

$\mathrm{Na}$ matriz dos problemas que pretendemos aqui levantar está a fabricação da ideia de “crise" que, na voz da grande mídia e dos grupos políticos que coordenam o Estado, tudo justifica e tudo autoriza, inclusive sufocar, imobilizar, deteriorar, sucatear, impedir o funcionamento, impondo racionamentos e construindo argumentos que atestam a irrelevância das universidades públicas e demais instituições afins. São elas, no caso do Rio de Janeiro, que recebem o primeiro corte, o primeiro atraso de pagamento, a falta de informação ${ }^{1}$. A Secretaria de Ciência, Tecnologia e Inovação - que no exercício da crise passou a se chamar Secretaria de Ciência, Tecnologia e Desenvolvimento Social, depois de uma fusão com a Secretaria de Assistência Social e Direitos Humanos - é sempre a primeira a receber o sinal do desfinanciamento público. Subordinada a essa secretaria estão, no âmbito da Ciência e da Tecnologia, a Universidade do Estado do Rio de Janeiro (UERJ), a Universidade Estadual do Norte Fluminense Darcy Ribeiro (UENF), a Universidade Estadual da Zona Oeste (UEZO), a Fundação Centro de Educação a Distância e Divulgação Científica (CECIERJ), a Fundação de Apoio a Escola Técnica (FAETEC) e a Fundação de Amparo a Pesquisa do Estado do Rio de Janeiro (FAPERJ) ${ }^{2}$. Em tempos de "crise", cuja razão principal, de acordo com a narrativa oficial, é a queda na arrecadação dos royalties do petróleo, devemos indagar por que uma secretaria, que poderia nos auxiliar a escapar dessa situação de dependência, é exatamente uma das mais prejudicadas? Por que as ações “emergenciais", devido ao decreto de calamidade pública ${ }^{3}$, atingem principalmente as instituições de nível superior? ${ }^{4}$

Para que serve, afinal, a universidade? Qual o seu projeto? Universidade para quem? Estas perguntas, feitas por Darcy ao longo da segunda metade do século XX, ainda carecem de respostas e podem ser - é a nossa aposta - decisivas para a compreensão da chamada "crise" que vivemos no estado.

\section{Sobre as crises da universidade}

Revista Interinstitucional Artes de Educar. Rio de Janeiro, V. 3 N.2 - pag 47-63 (jul/out2017): "Número Esperial Darcy Ribeiro" DOI: 10.12957/riae.2017.31712 
O noticiário televisivo, os jornais e revistas impressos, as postagens em redes sociais online e as manifestações em diferentes pontos da cidade e do estado - só para citar alguns exemplos dão conta de que o Rio de Janeiro encontra-se em "crise" ou, pelo menos, o conjunto das narrativas oficiais que busca comunicar o que acontece hoje em terras fluminenses anuncia que a palavra adequada para classificar o tempo presente é esta: “crise". Crise generalizada, em todos os setores, exigindo medidas amargas, entre elas a perda de direitos dos trabalhadores, um prato cheio para decisões extremas que, em tempos de normalidade, pareceriam absurdas. O estado de calamidade, que confere permissibilidade e exceção, é vendido como a solução de todos os problemas, só que entre os problemas também há seleção e são, geralmente, as universidades e as instituições que viabilizam e praticam o ensino superior, as primeiras a serem deixadas de lado.

Neste trabalho, nos limites que a escrita nos impõe, concentraremos nossos esforços em um aspecto desta "crise" anunciada: os efeitos percebidos nas instituições de Ensino Superior do estado, sobretudo aqueles que são consequência direta da falta de investimento que dificulta e/ou impossibilita a manutenção das universidades, seja no que tange a viabilidade dos serviços básicos de limpeza, segurança e alimentação ${ }^{5}$, seja no atraso de salários que coloca os servidores públicos do estado em situação de penúria. A tentativa de inviabilização de tais unidades também se mostra na negação do custeio básico para os projetos que justificam cada órgão. Com os projetos parados, os órgãos perderiam suas funções, abrindo caminho para contestações de o porquê da sua existência.

Ao fazermos uma incursão nesses dilemas, apoiaremos nossa escrita não apenas nos textos de Darcy Ribeiro mas também, em menor medida, de Boaventura de Sousa Santos, tomando suas leituras sobre a crise e a função das universidades para pensarmos o contexto atual e os diferentes atores que disputam o protagonismo das narrativas que dariam conta deste cenário.

Um primeiro movimento que nos parece necessário esmiuçar é pensar que características o discurso de "crise" assumiria nas universidades, prestando bastante atenção na profusão de narrativas que enxergam a universidade como um problema - e não como espaço de invenção das soluções.

Em a Universidade Necessária (1975), Darcy Ribeiro analisa como a universidade poderia ser um impulso definitivo para a criação de um modelo de desenvolvimento autônomo, que não apenas refletisse modelos pré-concebidos nos principais centros econômicos e políticos do mundo, mas que fosse pensado sob medida para as demandas do país. Nas palavras de Darcy, a universidade seria um poderoso instrumento para que nos libertássemos de certo tipo de desenvolvimento pautado em uma "atualização histórica" - em que povos supostamente atrasados passam a se inserir nos códigos e nas estruturas pensadas pelos ditos sistemas superiores. Contrário Revista Interinstitucional Artes de Educar. Rio de Janeiro, V. 3 N.2 - pag 47-63 (jul/out2017): "Número Esperial Darcy Ribeiro" DOI: $10.12957 /$ riae.2017.31712 
a essa ideia, Darcy apostava na universidade como centro de produção de uma "aceleração evolutiva" (RIBEIRO, 1975:15), modelo de desenvolvimento autônomo, segundo o qual as sociedades mobilizam fatores endógenos e exógenos de acordo com as suas peculiaridades históricas.

A concepção de Darcy sobre a universidade passa, então, pela construção de um modelo a ser desenvolvido pela reflexão e ação intelectuais. Segundo ele:

A Universidade de que precisamos, antes de existir como um fato no mundo das coisas, deve existir como projeto, uma utopia, no mundo das ideias. Nossa tarefa, pois, consiste em definir as linhas básicas deste projeto utópico, cuja formulação deverá ser suficientemente clara e atraente para poder atuar como força mobilizadora na luta pela reforma da estrutura vigente. (RIBEIRO, 1975, p.172).

Partícipe privilegiada na elaboração de um projeto de nação, a universidade não passaria incólume pelas reações dos grupos para os quais ela poderia representar algum perigo. Darcy entendia que a universidade no Brasil experimentaria crises de diversas ordens, cabendo aos intelectuais, comprometidos com ela e com o país - já que o país é a causa principal da universidade - superar as adversidades em nome do seu compromisso histórico: contribuir para o desenvolvimento científico e econômico do Brasil. As universidades, agentes da transformação por via do trabalho dos intelectuais, enfrentavam, segundo Darcy, uma crise aguda de ordem conjuntural, política, estrutural, intelectual e ideológica.

A crise conjuntural estaria ligada à defasagem das universidades nos países semiperiféricos e periféricos em relação ao desenvolvimento do conhecimento científico nos países centrais, em especial depois de revoluções como a técnico-científica e o avanço das tecnologias da informação e da comunicação. O baixo financiamento científico e tecnológico, praticado em países como o Brasil, nos colocaria em posição desfavorável em relação a esses países mais desenvolvidos.

Em termos políticos, a crise se daria entre grupos sociais cujos interesses seriam antagônicos, exercendo, cada qual, sua influência sobre os rumos e a função da universidade, às vezes compreendendo-a como um espaço conservador e de manutenção da ordem, outras vezes com uma visão progressista e até mesmo revolucionária. Atualmente, por exemplo, há grupos da sociedade civil organizada que acusam a universidade de ter certa inclinação à esquerda, e tais grupos produzem narrativas que defendem um ensino neutro, tecnicista e apartado dos problemas sociais. Nas manifestações travestidas de verde e amarelo, com presença maciça de grupos da direita, o nome de Paulo Freire aparece como a personificação do inimigo, abrindo caminhos para o aumento da influência de projetos como o Escola "sem" Partido e para ideias neoliberais, como a cobrança de mensalidade nas universidades públicas. Ao mesmo tempo, os grupos progressistas constroem também nas universidades pontos de resistência, contrários ao golpe de estado de 2016 
e às reformas trabalhista e da previdência, atualmente em voga no Congresso Nacional.

A crise, para Darcy, também seria de ordem estrutural, pois em países como o Brasil o funcionamento das universidades sofreria os constrangimentos e obstáculos comuns aos países em desenvolvimento. Os problemas da trajetória histórico-institucional do Brasil também seriam, assim, percebidos pelas universidades aqui instaladas. Esse passivo era um dos argumentos centrais para Darcy propor um novo modelo universitário, dado o "vício de origem" das universidades brasileiras - classistas, racistas, pautadas em privilégios que constituem um verdadeiro projeto de exclusão social pela educação. Darcy argumentava: “[...] só uma universidade nova, inteiramente planificada, poderá estruturar-se em bases mais flexíveis e abrir perspectivas de pronta renovação de nosso ensino superior” (RIBEIRO, 1975, p. 15).

Para ilustrar a desigualdade social ratificada pela universidade, Darcy analisava o número de ingressantes no ensino superior em comparação àqueles formados no ensino básico e médio. Segundo ele, a “[...] ampliação das bases sociais em que os candidatos são selecionados é uma das missões da universidade brasileira que, enquanto não puder cumpri-la, estará em débito com o Brasil” (RIBEIRO, 1962, p. 14). O débito, apesar de menor hoje em dia, ainda é gigantesco.

Darcy também apontava para o fato da universidade brasileira falhar na oferta de cursos que poderiam ser decisivos para o progresso do país. Neste ponto, é importante sublinhar que a visão de progresso do autor passava por certo comprometimento da universidade com a formação de mão de obra especializada para o mercado, algo que podemos contestar atualmente, mas que naquele momento, devido às circunstâncias políticas em que Darcy estava inserido, era plenamente justificável. As universidades, em um processo constante, estariam:

Divorciando-se das necessidades da formação da força de trabalho, dos tecnólogos, dos cientistas e dos sábios, com os tipos de preparo intelectual e de treinamento requeridos para promover o progresso social e cultural da nação, a universidade se reduz a mera agência de atribuição e de ratificação de status, só capaz de contribuir para a perpetuação da ordem social no que ela tem de iníquo, para atar a imensa maioria dos brasileiros a condições de atraso e de penúria que contrastam gritantemente com o desenvolvimento de outros povos. (RIBEIRO, 1962, p. 32-33).

Darcy compreendia que o Brasil do século XX, formado por uma sociedade em franca transformação em termos culturais e econômicos, precisava de uma nova universidade, capaz de integrar ensino e pesquisa e caminhar junto com essa sociedade em seus avanços tecnológicos, optando por um modelo de desenvolvimento atrelado ao conhecimento científico. Dizia ele:

Agora que já produzimos aço, telefone, penicilina e com isso muito acrescentamos à nossa autonomia, caímos em novo risco de subordinação, 
representada pela dependência das normas e de saber de técnicos. Só seremos realmente autônomos quando a renovação das fábricas aqui instaladas se fizer pela nossa técnica, segundo procedimentos surgidos do estudo de nossas matérias primas e de nossas condições peculiares de produção e de consumo. Só por este caminho poderemos acelerar o ritmo de incremento de nossa produção, de modo a reduzir e, um dia, anular a distância que nos separa dos países tecnologicamente desenvolvidos e que se apartam cada vez mais de nós pelos feitos de seus cientistas e técnicos. (RIBEIRO, 1975, p. 17).

Por fim, para Darcy, a crise da universidade seria também intelectual e ideológica, pois ao reunir pessoas de trajetórias e classes distintas, ela fomentaria discursos e práticas possivelmente antagônicos. Há no Ensino Superior pessoas que pensam o papel da universidade em termos de transformação da realidade social e, ao mesmo tempo, habitam o espaço universitário representantes de um pensamento mais conservador, que defendem a manutenção de certa hierarquia dos saberes e que julgam as políticas de acesso a esse nível educacional como inoportunas e propagadoras de uma queda da qualidade do ensino. É o que vemos, por exemplo, nas reações contrárias às políticas de cotas.

As crises possuem, para Darcy, correlação direta com o projeto de nação que se quer desenvolver e sua superação viria, para ele, com a compreensão do papel desempenhado pela universidade: se ela estaria ao lado daqueles que pregam a manutenção do status quo, buscando se enquadrar naquilo que vem sendo desenvolvido em outros países ou se, ao contrário, ela se constituiria em instrumento fundamental para a mudança social, em um esforço para derrotar o neocolonialismo que, em tempos atuais, se disfarça de imposições externas como, por exemplo, de instituições financeiras internacionais como o Banco Mundial.

Boaventura de Sousa Santos, em sua análise sobre as crises da universidade no século XXI, também identifica determinados processos de crise pelos quais países como o Brasil passam. Para Santos (2005) trata-se, em primeiro lugar, de uma crise de hegemonia, visto que ao propósito inicial das universidades - que era formar as elites da sociedade - acrescentou-se, nas contingências do capitalismo, a formação de mão de obra qualificada para o mercado. Para cumprir tal demanda, crescente e nem sempre viável para a Academia, agentes econômicos e o próprio Estado irão buscar em outros espaços/tempos oportunidades de concretização deste objetivo, restando à universidade disputar espaço com outras instituições, como as escolas técnicas, por exemplo. Para Santos houve, nos últimos anos, uma falsa resolução da crise de hegemonia, visto que a universidade deixou de ser um lócus exclusivo de lapidação da intelectualidade, dedicandose, mais especialmente, a formar mão de obra para o mercado. Tal fato dá a entender que a universidade estaria mais aberta às diversas classes sociais, deixando de ser um reduto exclusivo das elites. Mas esse processo ainda está longe de se apresentar como satisfatório. 
Outra vertente da crise, ainda de acordo com Santos (2005), seria a crise de legitimidade, pautada na seguinte contradição: se, por um lado, a universidade produz certos tipos de saberes/fazeres, legitimados pela própria Academia, contribuindo, assim, para a hierarquização do conhecimento - privilegiando uns poucos se consideramos as inúmeras restrições de chegada à formação superior - por outro lado, diante das exigências políticas e sociais, há uma demanda por democratização do acesso e igualdade de oportunidades. Nos últimos anos, ainda que seja crescente a desvalorização do diploma universitário, a universidade mantêm-se como reduto de classes privilegiadas que, a sua revelia, testemunham as novas caminhadas daqueles que, historicamente, costumavam servir de combustível nas máquinas de moer gente (RIBEIRO, 1995b). As políticas de cotas, ao mudar a cor e a classe das universidades, inseriram um fator novo na apreensão que temos do ensino superior. Contudo, longe de resolver alguma crise, tal processo de inclusão a aprofunda. A mudança parcial de cenário oferece, segundo Boaventura, uma falsa resolução da crise de legitimidade, que será agravada, como veremos, pela crise institucional do século XXI.

Santos (2005) argumenta também que há, entre nas universidades, uma crise institucional, fruto da crise financeira, que coloca para as universidades um desafio: ao mesmo tempo em que pleiteiam autonomia político-administrativa, as universidades se vêem pressionadas pelo capital a praticar critérios de eficiência e produtividade, aproximando-se do modelo empresarial. Como argumenta Boaventura, a crise financeira, causa direta da institucional, é legitimada pelos organismos financeiros internacionais, como o Banco Mundial:

[...] O caso do Brasil é representativo da tentativa de aplicar a mesma lógica na semiperiferia e, por ser bem conhecido, dispenso-me de o descrever. Basta referir o relatório do Banco Mundial de 2002 onde se assume que não vão (isto é, que não devem) aumentar os recursos públicos na universidade e que, por isso, a solução está na ampliação do mercado universitário, combinada com a redução dos custos por estudante (que, entre outras coisas, serve para manter a pressão sobre o salário dos docentes) e com a eliminação da gratuidade do ensino público, tal como está agora a ocorrer em Portugal. (SANTOS, 2005; 14).

Santos previu, quando escreveu inicialmente sobre as crises, há dez anos, que a crise institucional seria central. Nos últimos anos cresceu a compreensão de que a universidade pode ser um bem público, porém não assegurado exclusivamente pelo financiamento do Estado. Assim como notamos na "crise" atual do estado do Rio de Janeiro, houve uma crescente desvalorização da universidade enquanto prioridade dos investimentos públicos. Santos argumenta que no caso do Brasil: 
O processo expansionista de industrialização, quase totalmente assente no endividamento externo, entre 1968 e 1979, conduziu, sobretudo após 1975, a uma profunda crise financeira, cujos efeitos se tornaram particularmente graves após 1981-1983 [...]. A crise financeira do estado repercutiu-se de forma brutal sobre a universidade pública, tanto mais que simultaneamente aumentou a demanda social pela expansão da educação básica. (SANTOS, 2005;8).

A crise financeira, pelo endividamento público do período da ditadura civil/militar, abriu espaço para a aplicação do ideário neoliberal no Brasil. Uma consequência de tal movimento foi a subordinação do investimento público às demandas do mercado, privilegiando agentes privados em detrimento das políticas públicas. Tudo isso assentado na compreensão, que não encontra apoio em dados comprobatórios, de que a iniciativa privada aloca mais racionalmente os recursos do que o Estado.

A universidade, que não é uma empresa e nem sempre possui, necessariamente, em seus quadros especialistas em administração ou economia, vê-se com a tarefa de gerenciar uma alardeada autonomia que é, na verdade, discursiva, visto que cabe ao Estado - no caso do Rio de Janeiro, pelo menos - definir as formas de utilização das verbas disponíveis, tendo a universidade pouco ou quase nenhum espaço para desenhar suas prioridades. Bruno Sobral (2017) nos lembra que as universidades estaduais gozam, de acordo com a constituição do estado do Rio de Janeiro, de dotação orçamentária própria, na forma de duodécimos mensais de $6 \%$ do orçamento ${ }^{6}$.

Dito isto, podemos concluir que um dos problemas mais graves que circundam a universidade contemporânea tem a ver com o seu financiamento. A universidade, na visão das nossas elites e dos nossos dirigentes político-empresariais, não é território do povo, não é bem de primeira necessidade para quem tem precisão de tantas outras coisas. A universidade é complemento, é privilégio, é lapidação do capital cultural e, como tal, é mais indicada e viável para quem ocupa posições sociais mais elevadas.

Assim, em meio a classes descartadas, forma-se um quadro difícil de ser modificado: os bem nascidos, os afortunados vão ocupando os espaços de privilégios. E os excluídos - esperam os ideólogos das desigualdades - devem aceitar isto de bom grado.

A obrigação do Estado, de acordo com os analistas da crise - que ao analisarem a inventam - poderia ficar restrita à oferta da educação básica, garantindo uma entrada reduzida do povo pobre na cultura letrada. Se quem não tem dinheiro desejar seguir adiante, precisará traçar um caminho próprio, buscando com os meios de que não dispõe, as oportunidades negadas a quem não tem direito a um lugar ao sol.

Tal pensamento, construído em torno da teoria do capital humano, ganha reforço nas indicações do Banco Mundial - aquela agência acostumada a cuidar do quintal alheio e que, de 
tempos em tempos, mostra sua força e sua influência nos países que acreditam depender de suas ideias para sair de alguma crise - crise que quando não existe é fabricada sob medida para as soluções enlatadas de algum salvador externo ligado ao grande capital.

Relevante é registrar que a construção ideológica da noção de capital humano, ao mesmo tempo em que induz a uma visão invertida da desigualdade, estabelece uma mudança profunda e regressiva na concepção republicana de educação básica, pública, gratuita, universal e laica. A educação escolar deixa de ser concebida como um direito social e subjetivo universal e, se é definida como investimento em capital (capital humano), passe a reger-se pelos critérios e leis mercantis. (FRIGOTTO, 2017, p. 27).

O que se vê, neste cenário em que tudo vai muito mal, é um esforço dos governos - quase sempre acompanhados da grande mídia e de grupos empresariais - para disfarçar os sinais de que as prioridades do Estado, tomado por grupos de interesse, têm sido pagar a dívida pública e manter uma política esdrúxula de isenções fiscais para grandes conglomerados financeiros. Falta dinheiro para pagar os salários dos servidores públicos, mas um montante muito maior é dispensado para manter acordos e negociatas firmados em tempos de campanhas eleitorais; өnde essas mesmas empresas agraciadas com as isenções fiscais, muitas vezes, patrocinaram candidaturas, viabilizando a atuação política de quem hoje lhes estende a mão. No caso das isenções, é salutar sublinhar que não há, por parte do Estado, um acompanhamento sobre investimentos e geração de empregos, não podendo ser viável mensurar o impacto positivo que tais facilidades fiscais ofertadas às empresas geram na sociedade. O discurso do governo é que tais medidas são necessárias para manter e fazer crescer os índices de empregabilidade, mas, ao mesmo tempo, não é capaz de dizer o quanto isso de fato significa.

Diante de tantas desigualdades de tratamento, não é de se espantar que a adesão popular à luta das universidades públicas no Estado do Rio de Janeiro seja tão tímida como tem sido. Entre os efeitos da "crise" há uma ausência de representatividade, pois, em uma sociedade dividida entre estabelecidos e outsiders, fica praticamente impossível convencer quem está fora da importância que é manter aquele reduto de tão poucos. Decerto, nos últimos anos, com o avanço - insuficiente, porém grandioso - das políticas de acesso produzidas pelos governos Lula da Silva e Dilma Rousseff, a universidade deixou de ser palco exclusivo das elites e abriu-se para estratos da sociedade historicamente marginalizados, mas a narrativa desta entrada crescente de pretos e pobres no Ensino Superior foi sequestrada pelas transmissões parciais da grande mídia e, em considerável medida, foi silenciada por grupos pretensamente progressistas que, estando à frente de alguns sindicatos e de determinadas correntes dos movimentos sociais, sublinham os erros dos governos petistas, ao passo que ocultam avanços importantes. 
Mas, a despeito do que falam delas, as universidades jamais serão como antes, encontramse tomadas por ações de resistência, embora ainda não saibam como mobilizar os demais setores da sociedade para que saiam em sua defesa. A universidade, por muito tempo enclausurada e inacessível às classes desprivilegiadas, vê-se tomada pelas gentes das cotas e das políticas públicas dos governos petistas. Trata-se de uma conquista pouco digerida pelas classes dominantes que, diferente de antes, agora têm que conviver em seus trajetos habituais com os sinais dos novos tempos. Longe de termos uma inclusão satisfatória dos atores até então excluídos da história das universidades, é público e notório que há um quantitativo que invade, ocupa, ressignifica a paisagem sempre tão branca e endinheirada do Ensino Superior.

O novo cenário, na análise de Frigotto (2017), estimula o revanchismo contra o avanço das camadas populares. Fora dos seus lugares historicamente estabelecidos, favorecidos pela Constituição de 1988, sobretudo no que tange ao direito à educação, e também beneficiados pelo conjunto de mudanças iniciadas com a posse de Lula da Silva em 2003, esse público que viu finalmente chegar a sua vez na fila dos direitos sociais, agora convive com a marcha do retrocesso. A emergência de um pensamento conservador, cujo progresso mais evidente é o projeto Escola "sem" partido, vai destruindo pouco a pouco a ainda insuficiente inclusão dos mais pobres. Ideias de privatização e de restrição ao acesso ao Ensino Superior, dão a tônica das saídas propostas para vencer a "crise" - uma crise desenhada a mão, à luz do dia, por atores que perderam o pudor ao estancar a sangria que impunha algum risco para os seus malfeitos. A perda de direitos é manchete secundária nos jornais e nas revistas, sendo a onda conservadora e privatista navegada como recurso inevitável. Todo esse processo é chancelado, muitas vezes, por interesses privados dos maiores grupos de comunicação do país, adeptos do pensamento neoliberal e contrários aos avanços de direitos em geral. A “crise” é editada, roteirizada e veiculada pela televisão.

\section{A crise televisionada}

Bourdieu, em Sobre a Televisão (1997), analisa que esse dispositivo tecnológico e cultural representa um desafio tanto para a política cultural quanto para a democracia, podendo se tornar um "instrumento de opressão simbólica" (BOURDIEU, 1997. p. 13). Para ele, mesmo quando oculta fatos, a televisão seleciona como mostrará a realidade, influenciando-a diretamente. Tudo sob a lógica comercial que determina a busca por índices de audiência a fim de atrair anunciantes e aumentar os lucros da empresa de comunicação.

No Rio de Janeiro da "crise”, anunciada desde 2015, a TV - e suas múltiplas formas de consumo - bem como os novos dispositivos digitais, possui um papel decisivo na publicização da "crise" espetacularizada. Ao mesmo tempo em que se produzem conteúdos que narram a difícil 
jornada dos servidores com salários atrasados e com vidas inviabilizadas, tais empresas de comunicação constroem em seus discursos a visão de que o Estado não tem condições de arcar com o financiamento básico de alguns serviços, com destaque para aqueles prestados pela pasta de Ciência, Tecnologia e Inovação. Ao final de 2016, por exemplo, ao mesmo tempo em que noticiava a Campanha de Natal do Movimento Unificado dos Servidores Públicos Estaduais $(\text { MUSPE })^{7}$, para a qual os servidores arrecadaram e distribuíram cestas básicas para outros servidores em situação de fome, a mídia em geral destacava como o poder público inviabiliza instituições de ensino superior como a UERJ, em uma abordagem que deixa subentendida a ideia de que o ensino superior não é viável enquanto público.

\section{O papel da universidade e dos intelectuais}

Essa inviabilização teórica e midiática do ensino superior entra em choque com o projeto de universidade defendido por Darcy. Para ele, a universidade deveria ter um projeto político e pedagógico claro de inclusão e transformação social, impactando decisivamente no projeto de nação almejado. Um dos objetivos da universidade seria interpretar a modernidade e produzir um autoconhecimento da sociedade nacional, promovendo seu desenvolvimento autônomo. Outro objetivo seria aumentar e diversificar a formação, prestando atenção às demandas de cada região onde a universidade será instalada.

Nesse sentido, os intelectuais teriam papel de destaque, pois sua mentalidade utópica poderia, a partir do projeto de transformação social da universidade, influenciar diretamente a realidade. Seriam os intelectuais que deveriam decidir o projeto utópico de universidade, substituindo o senso comum pelo conhecimento científico e, assim, permitindo que não se reproduzam, simplesmente, modelos externos de desenvolvimento. A influência dos intelectuais se daria pela reflexão e pela ação direta na sociedade - o pensamento-ação de Darcy - por supostamente terem o preparo necessário para promover o progresso a partir do conhecimento científico e por serem capazes de mobilizar a sociedade e mudar a ordem vigente. Entretanto, os vários exemplos acumulados ao longo da nossa história comprovam que, em relação aos intelectuais, Darcy estava equivocado ou, pelo menos, tenha superestimado em demasia as suas habilidades e senso de altruísmo. Os intelectuais têm pertencimentos de classe, interesses políticos e visões variadas sobre o sentido da universidade.

Tamanha mudança almejada por Darcy não viria sem resistência. Sendo a universidade um local de produção do saber, torna-se um perigo para o status quo e deve, como tal, ser combatida. Darcy Ribeiro entendia a função social da educação como um agente do saber e 
Saber é isto: uma força, uma arma. [...] Ciência falsa e mediocridade nada são, nada podem. No caso da universidade, este desafio científico aponta para o dever de evitar que se cultive um saber fútil, inútil. Que seja esse saber brincadeira de tantos acadêmicos universitários, em que um escreve para o outro. (RIBEIRO, 1995, p. 20).

A expansão da universidade seria um imperativo para a superação das desigualdades, impactando diretamente na melhoria do ensino fundamental e básico. Todavia, da mesma forma que pode ser um projeto de ação e reflexão dos intelectuais, pensado para impactar positivamente a sociedade, o fracasso desse modelo seria um projeto deliberado das classes dominantes para a perpetuação das desigualdades e da subordinação a um modelo de atualização histórica.

Ademais, é importante ressaltar que, mesmo tendo as elites, no argumento de Darcy, planejado a educação das massas para ser um fracasso, no miudinho do dia a dia, nos espaços/tempos que vão sendo ocupados, há resistências e criação de horizontes novos. A revolução social nem sempre aguarda a ação dos intelectuais, sendo múltiplas as suas fontes de produção, sendo várias as ações dos movimentos sociais que passam a redesenhar as paisagens do ensino superior, com destaque para os movimentos de mulheres, negros e LGBTT que pleiteiam, cotidianamente, não apenas com ações reivindicatórias, mas com seus corpos que desafiam a ordem, uma universidade mais justa e inclusiva.

O projeto de Darcy, ainda marcado pela modernidade como ressaltamos no início do texto, trazido para a realidade atual poderia deixar de lado o fato de termos resistências a partir de camadas populares da sociedade, longe da intelectualidade universitária, ainda elitista e excludente. Por exemplo, os Movimentos dos Trabalhadores Sem Teto e dos Trabalhadores Sem Terra que possuem modelos de educação próprios e que hoje tem, em diversas ocasiões, capacidade de mobilização popular maior do que o de grupos intelectuais organizados.

\section{A universidade, a ecologia dos saberes e a saída da crise}

Para Darcy, a transformação social se concretizaria a partir da ação direta da universidade, que refletiria sobre problemas locais e regionais, reforçando o potencial econômico e induzindo o desenvolvimento na localidade. A UENF, com seus cursos voltados majoritariamente para o estudo da produção e exploração do petróleo - abundante na região de Campos dos Goytacazes e Macaé - é um exemplo claro dessa estratégia. Porém, não podemos desconsiderar que a universidade não é o único agente capaz de produzir mudanças locais, sendo fundamental observar a complexidade de atores que se apresentam como resistência diante dos modelos de atualização histórica. 
Santos (2007), pensando nessa diversidade de práticas e conhecimentos, cunhou o termo ecologia dos saberes a partir da compreensão de que precisamos de uma epistemologia do "sul global", ou seja, a periferia mundial, fruto de colonizações recentes ou mais antigas, onde ocorreu não só o domínio político-econômico, mas também epistemológico que perdura até hoje. A ecologia dos saberes seria um conjunto de epistemologias marcadas pela possibilidade da diversidade de pensamento fora do eixo central, como resistência à globalização neoliberal, exercendo diretamente o papel de globalização contra-hegemônica. Na ecologia dos saberes há a valorização não apenas do conhecimento científico-acadêmico, mas da interação deste com o conhecimento produzido localmente, o que contribuiria para fortalecer e dar credibilidade à produção do conhecimento em geral. Darcy, apesar de acreditar na superação da cultura popular que aparece neste ponto da sua obra como sinônimo de senso comum que deveria ser superado pelo conhecimento científico - exaltou os saberes locais ao formular as ações educativas dos CIEPs. Nos Centros Integrados de Educação Pública, referência na oferta de ensino de tempo integral para as classes populares, o autor de O Povo Brasileiro, elegia a animação cultural como disciplina de integração entre a escola e a comunidade, devendo ser o animador cultural um membro desta comunidade e um guardião dos seus saberes/fazeres que mereciam ser propagados.

O projeto de animação cultural desenvolvido nos CIEPs, utilizando artistas da própria comunidade, teve essa preocupação básica de valorização e resgate de nossa própria cultura, assim como o de conseguir através do trabalho cultural a integração da comunidade à escola. (FARIA, 1991, p. 24).

Para Santos, as produções epistemológicas devem se debruçar nas práticas de conhecimento e seus efeitos na sociedade, em um movimento similar ao pensamento-ação de Darcy, e não sobre o pensamento abstrato, dito neutro, pois: "não há epistemologias neutras e as que reclamam sê-lo são as menos neutras" (SANTOS; MENESES, 2010, s/p).

Portanto, a transformação da sociedade viria da comunhão de uma ecologia dos saberes capaz de se contrapor à hegemonia neoliberal, pautada nas resistências e nas táticas de praticantes (CERTEAU, 1994), dos atores escolares e acadêmicos, dos sindicatos e dos movimentos sociais, em que podem participar os intelectuais da universidade (ou não). Ainda que tenha um papel central na construção de um projeto de nação - na visão de Darcy - ou na produção de uma contra hegemonia aos anseios neoliberais - na concepção de Boaventura - a universidade não fará nada sozinha, ao contrário, demandará ser cada vez mais ocupada pela gente historicamente excluída, abrindo-se à diversidade e minimizando as disparidades que ainda hoje conhecemos.

\section{Considerações finais}


Compreendemos a "crise" atual não apenas do estado do Rio de Janeiro, mas de todo o país, como construção discursiva e como estratégia para os anseios mais conservadores, especialmente àqueles mais conectados com a elite financeira nacional e internacional.

No cerne deste discurso, há uma demanda histórica dos grupos conservadores pela diminuição do papel do Estado na oferta do ensino superior, sendo cruciais para isso as recomendações do Banco Mundial, para quem o Estado deveria se limitar a investir no ensino básico e fundamental.

Nesse sentido, compreendemos a "crise" do estado do Rio de Janeiro, deflagrada em 2015, como um laboratório de experimentação do projeto de desfinanciamento da educação, com destaque para o ensino superior.

É imperativo ressaltar, entretanto, frente à crença que Darcy Ribeiro depositava nos intelectuais como promotores da mudança, que eles - os intelectuais - possuem seus pertencimentos e que nem sempre reconhecem na universidade o lócus da transformação social, dialogando com pensamentos mais conservadores. No cenário atual multiplicam-se os discursos de professores e juristas que apostam nos investimentos privados como soluções plausíveis para a "crise" enfrentada pela Academia. Em suma, o que essas vozes acadêmicas ressoam é a possibilidade do compartilhamento entre investimentos públicos e privados, algo que, para Darcy, comprometeria a lisura da pesquisa devido aos interesses de quem a financia, contribuindo para os processos de servidão do conhecimento nacional aos modelos produzidos no estrangeiro.

A associação do Estado com grupos midiáticos, que reforça a narrativa da "crise" e oculta suas causas e seus efeitos é também um ponto que merece a nossa atenção. Ainda que a grande mídia, em alguns momentos muito pontuais, dedique suas páginas e telejornais a dar visibilidade aos problemas enfrentados pelos servidores públicos do estado do Rio de Janeiro, o conjunto de narrativas diretamente veiculado em seus vários canais vão produzindo sinais de esgotamento do Estado frente ao financiamento da educação pública, sendo este um caminho propício para a indicação do setor privado como salvador da pátria.

A “crise” no estado do Rio de Janeiro é uma espécie de laboratório de um modelo de ciência e tecnologia que deve ser adotado por outros estados. A lógica do financiamento privado, que aproxima as universidades do modelo empresarial, representa o avanço da globalização neoliberal que, em última instância, impede o projeto de nação pensado por Darcy, ignorando as dissidências apontadas por Boaventura.

Como indica Santos, a crise financeira impacta diretamente nas demais, pois ao adotar uma lógica empresarial de busca de diminuição de custos para obtenção de lucros cada vez maiores, ou seja, a dita eficiência do mercado, diminui-se cada vez mais o acesso de quem não pode custear os Revista Interinstitucional Artes de Educar. Rio de Janeiro, V. 3 N.2 - pag 47-63 (jul/out2017): "Número Esperial Darcy Ribeiro" DOI: $10.12957 /$ riae.2017.31712 


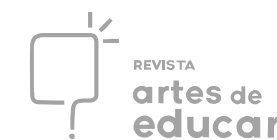

estudos de ensino superior (ou aumenta o endividamento necessário para isso), acentua a falta de autonomia da universidade para decidir seu próprio projeto político pedagógico ao subordiná-la a metas de produtividade e agrava os obstáculos estruturais ao seu pleno funcionamento, com a consequente precarização do trabalho.

A luta pelo ensino superior público de qualidade não pode prescindir da adoção de uma ecologia dos saberes, ou seja, será preciso considerar as epistemologias que falem a partir do local, comprometidas com a mudança e com a resistência ao modelo hegemônico de globalização, sem desconsiderar o saber popular em conjunto com o conhecimento científico. Decerto, essa proposta terá resistência na onda conservadora que se expressa, por exemplo, no programa escola "sem" partido, que visa reduzir o papel do professor a um mero transmissor de conteúdos previamente fabricados e supostamente neutros.

Deixamos, pois, como reflexão sobre a universidade necessária nos dias atuais as seguintes questões: qual o papel da universidade frente ao avanço da globalização hegemônica? Quais os limites e possibilidades dos intelectuais nas ações de mudança e como eles podem dialogar com a ideia de ecologia dos saberes para pensar práticas conjuntas de luta? Que visões de ciência e tecnologia estão em disputa na produção da "crise" do estado do Rio de Janeiro? "Crise" para quem? Universidade para quem?

\section{Bibliografia}

BOURDIEU, Pierre. Sobre a Televisão: seguido de A influência do jornalismo e Os Jogos Olímpicos. Rio de Janeiro: Jorge Zahar, 1997.

CERTEAU, Michel de. A Invenção do Cotidiano: 1. Artes de Fazer. Petrópolis, RJ: Vozes, 1994. FARIA, Lia. CIEP: a utopia possível. São Paulo: Livros do Tatu, 1991.

FRIGOTTO, Gaudêncio (Org.).. Escola "sem" partido: esfinge que ameaça a educação e a sociedade brasileira. Rio de Janeiro: UERJ, LPP, 2017.

RIBEIRO, Darcy. A universidade e a nação. In: Separata de Educação e Ciências Sociais, versão 10, nº 19, jan-abr, 1962.

. A Universidade Necessária. $2^{\mathrm{a}}$ ed. Rio de Janeiro: Paz e Terra, 1975.

. O Brasil como problema. $1^{\text {a }}$ ed. Rio de Janeiro: Global, 1995.

O povo brasileiro. $1^{\text {a }}$ ed. São Paulo: Companhia das Letras. 1995 b.

. A universidade no século XXI: para uma reforma democrática e

emancipatória da universidade. 2. ed. São Paulo: Cortez, 2005.

SANTOS, Boaventura de Sousa. Para além do pensamento abissal: das linhas globais a uma ecologia de saberes. Novos estudos. - CEBRAP, São Paulo, n. 79, p. 71-94, nov. 2007. 
Paulo: Cortez Editora, 2010.

; MENESES, Maria Paula. (Orgs.). Epistemologias do Sul. São

SOBRAL, Bruno Leonardo Barth. O sentido público de uma universidade como a UERJ. Disponível em http://www.jb.com.br/sociedade-aberta/noticias/2017/01/22/o-sentido-publico-deuma-universidade-como-a-uerj/ Acesso em 15 jul.2017.

\footnotetext{
${ }^{1}$ As notícias sobre o pagamento dos servidores são veiculadas primeiro na grande mídia, com destaque para o RJ TV $1^{\mathrm{a}}$ edição, da Rede Globo. O calendário de pagamento, antes de qualquer anúncio oficial, é informado pelo telejornal e, na maior parte das vezes, a Secretaria de Ciência, Tecnologia e Desenvolvimento Social não aparece na lista dos que irão receber.

${ }^{2}$ Darcy Ribeiro teve papel de destaque na formulação e/ou consolidação de algumas dessas instituições. Em primeiro lugar, a UENF, projetada por Darcy Ribeiro (batizada posteriormente com o seu nome, inclusive) seria a universidade dedicada ao desenvolvimento do interior do Rio de Janeiro. Em segundo lugar a UERJ, da qual foi reitor e buscou implementar sua visão sobre a "Universidade Necessária". Em terceiro lugar, o Consórcio CEDERJ, projeto comandado pela Fundação CECIERJ cuja inspiração adveio de Ribeiro que já antevia a importância da educação a distância para o processo de expansão do ensino superior de qualidade e público.

${ }^{3} \mathrm{O}$ "estado de calamidade pública" foi decretado no estado do Rio de Janeiro no dia 17 de junho de 2016 no Diário Oficial do estado. O decreto, prorrogado em 2017, visava honrar os compromissos estabelecidos com a organização dos jogos olímpicos e paralímpicos Rio 2016 e foi justificado com a queda da arrecadação de receitas, especialmente devido à queda internacional do preço dos royalties-do barril de petróleo.

${ }^{4}$ De Outubro de 2015 para cá (julho de 2017) a SECTI (atualmente SECTDS) teve, ao menos, 5 secretários em seu comando e caminha, no momento em que escrevemos esse texto, para a sexta mudança, o que revela o desprestígio atribuído à pasta no atual governo, a instabilidade que marca as instituições nela abarcadas (a FAETEC, por exemplo, teve no mesmo intervalo, semelhante fluxo de presidentes) e a falta de visão estratégica para a área.

${ }^{5}$ No caso da UERJ, o fechamento do Restaurante Universitário significou a impossibilidade de grande parte dos estudantes, professores e funcionários, realizarem suas refeições diárias. Sem bolsas e sem salários, equilibrando-se na corda bamba dos atrasos e dos calendários de pagamento não cumpridos, essas pessoas não têm como chegar à universidade, tão menos se manter dentro dela. O comércio do entorno, que poderia ser uma alternativa para as refeições do dia, também sente os efeitos do abandono da UERJ, tendo alguns deles fechado suas portas.

${ }^{6}$ Sobral (2017) argumenta que o texto da Constituição estadual "registra que a educação é um direito de todos e dever do Estado (artigo 306) e garante à UERJ estar organizada sob a forma de fundação de direito público e possuir dotação que deveria ser nunca inferior a 6\% da receita tributária líquida, a ser transferida em duodécimos mensais (artigo 309). Quanto ao último ponto, cabe esclarecer que essa vinculação de receita nunca foi admitida por causa da Adin 4.102 (com acórdão do STF publicado no inicio de 2015)". Cabe a ressalva que a lei faz referência ao ensino superior estadual e não apenas a UERJ. Disponível em http://www.jb.com.br/sociedade-aberta/noticias/2017/01/22/o-sentidopublico-de-uma-universidade-como-a-uerj/ Acesso em 15 jul.2017.

${ }^{7}$ O MUSPE é um movimento unificado de associações e sindicatos que representam os servidores públicos estaduais do Rio de Janeiro. O movimento foi reativado após o início da "crise" em outubro de 2015.
} 